EUROPE

\section{Ariane's price}

IF evidence is needed that the problems of international cooperation in science are more of ten political than scientific, the experience of the European Space Agency (ESA) is worth considering. Right now it is in the middle of its latest lurch towards compromise.

The immediate problem is moneyabout 7.7 million units of account (mua) of it ( 1 ua $=£ 0.622)$. That is the amount needed to cover the extra costs imposed by the decision to transfer the launch of the scientific satellite Exosat from a US Thor Delta rocket to ESA's own heavier Ariane launcher.

The decision was reached when ESA's Council met at the end of last month, and is frankly admitted to have been political. The original plan was for a Delta launch, and tenders for the spacecraft were submitted on that basis. But an Ariane launch was always possible, and Ariane is expected to have completed four development flights (three of them with payloads) by $1980-81$, when Exosat's mission of measuring cosmic X-ray sources is due to begin.

With so much money invested in Ariane and a flight available anyway, not to use it for Exosat would, it was felt, have reflected a lack of confidence. Recent unfortunate experiences with the Delta rocket, however-most spectacularly with Geos-have apparently had little influence.

When the change came, the decision was not unanimous. Ariane being a French project, France was its strongest supporter. Britain alone voted against, both in the Council and earlier in ESA's Science Programme Committee (SPC).

ESA's science advisory committee, which unlike the SPC and Council is not an executive body with national delegates, also resisted the idea. Its membership of six scientists considered the matter at the end of last year and expressed reservations about both the delay and the risk involved in an Ariane launch.

The worries are straightforward. The scientists want the satellite reliably placed in orbit as soon as possible. Estimates of the likely hold-up vary from three months to a year; it could be longer if Ariane itself goes awry, but if that happens it's probably back to the Delta. One scientist describes any delay at all as "very serious".

Meanwhile, ESA's Council meets again next week, to decide where the extra money will come from. The SPC says it can accept only 4 mua of the total. Britain objects to using funds already allocated for science on a launcher. Delays on Aerosat may ameliorate the problem, but a launch of a second Geos, at a cost of 14 mua, must also be considered. A decision on that is due in September. The options the Council has are not unacceptably limited, and some compromise seems possible. If so, it could be a prelude to something bigger later on if and when ESA's whole programme comes up for discussion.

Chris Sherwell

USSR

\title{
Messages from without
}

Vera Rich describes recent developments involving Soviet dissidents, and speaks to Mark Azbel

FORTY Western nuclear physicists attending the Tenth International Accelerator Conference in Dubna last week sent a message of sympathy to Dr Yurii Orlov, the physicist and dissident who since last February has been held incommunicado in the Lefortovo prison in Moscow in connection with his membership of the unrecognised 'Helsinki monitoring group'.

The scientists' action, on behalf of a colleague whose concern for academic freedom has led him into an active role in the human rights movement, reflects a growing concern with the fate of dissidents like Orlov and a recognition that such protests can be a way of offering genuine help. In the past certain scientists have expressed doubts that this type of action might only exacerbate an already dangerous situation, but since the Twentieth Party Congress in 1956 the Soviet authorities have shown a greater sensitivity to world public opinion, especially when that opinion is voiced by scientists. As Dr Evgenii Levich explained last week at a dinner in Oxford in honour of his father, who was unable to obtain a visa to attend his own 60th birthday conference, "The Soviet authorities are unable to imagine that there is any group of people as important as scientists".

This special status, of course, cuts both ways. According to Professor Mark Azbel, who for the past $2 \frac{1}{2}$ years ran the illegal Sunday seminar for refusnik scientists in Moscow, it is particularly difficult for physicists wishing to emigrate to receive visas. "I think that this is related to the fact that the Soviet officials are backward", he says; "they still remember only one thing-that the physicists were the ones who invented the nuclear weapons". For that reason, apparently, mathematicians (excluding applied mathematicians) generally find it easier to get exit visas than others. Not that mathematicians have it easy: Anatolii Shcharanskii, who for some time acted as spokesman of the Seminar and was an active member of the Moscow Helsinki group, is now facing a treason charge.

Azbel was finally allowed to emigrate two weeks ago. He told Nature: "I am infinitely happy to become, at last, a free man and a scientist in my native country (Israel). I am infinitely unhappy, however, when I think of all my many friends who are still living in a frightful situation which I know only too well". This, he said, amounted to "gradual scientific death because of the breaking off of scientific contacts, because of lack of laboratories, because of problems with publications, because of absence of conditions for scientific work, to say nothing of the destruction of the health of both the scientists and the members of their families because of the constant persecutions."

Azbel says there are still more than 100 refusnik scientists known personally to him, and that the total number "might be twice as large". This figure, of course, does not include dissidents who do not wish to emigrate. "Western scientists can do a lot," says Azbel, "as the Soviet authorities understand that collaboration with Western scientists is badly needed and that, at the same time, Western scientists do not depend on political fluctuations and that therefore they can hardly be influenced". He himself is certain that it was only due to "all those thousands of people throughout the world-both known and unknownwho supported us in our fight for scientific freedom ..." that he was finally granted a visa. He urged that each individual case of oppression of a scientist should be taken up by his colleagues.

Ironically, the Soviet Academy of Sciences adopted a resolution last February on the "moral responsibility" of scientists to help their less fortunate colleagues. This was proposed by Corresponding-Academician Veniamin Levich, who, although a refusnik, still keeps his position in the Academy. The resolution was accepted and, as Levich says, is therefore "difficult to ignore", even though it may have no effect on his personal fate. Still, while his birthday conference was taking place in Oxford, Academician A. A. Fedorov, visiting Britain as part of a "peace" delegation, made a statement which suggested that the constant barrage of protests was beginning to take effect in Levich's case. "I hope and believe," he declared, "that Levich will be able to leave the Soviet Union very soon."

- Ernest Akselrod, a psychiatrist formerly with the space programme, who was dismissed on applying for an exit visa to Israel and has since studied psychological and medical problems of refusniks, is to face trial for "parasitism" after refusing to take an alternative job. 